\title{
Immunoexpression of Ultraviolet Photoproducts and p53 Mutation Analysis in Atypical Fibroxanthoma and Superficial Malignant Fibrous Histiocytoma
}

\author{
Akio Sakamoto, M.D., Yoshinao Oda, M.D., Eijun Itakura, M.D., Yumi Oshiro, M.D., \\ Osamu Nikaido, M.D., Yukihide Iwamoto, M.D., Masazumi Tsuneyoshi, M.D. \\ Department of Anatomic Pathology, Pathological Sciences (AS, YoO, EI, MT), and Department of \\ Orthopaedic Surgery (YI), Graduate School of Medical Sciences, Kyushu University, Fukuoka, Japan; \\ Department of Pathology, Matsuyama Red Cross Hospital (YuO), Matsuyama, Japan; and Division of \\ Radiation Biology, Faculty of Pharmaceutical Sciences (ON), Kanazawa University, Ishikawa, Japan
}

p53 mutation is one of the major results of ultraviolet (UV) radiation. UV photoproducts of cyclobutane pyrimidine dimers (CPDs) and pyrimidinepyrimidone (6-4) photoproducts (64PPs) also play an important role in skin cancer development. Atypical fibroxanthoma (AFX), which mimics malignant fibrous histiocytoma (MFH) histologically, occurs in the sun-exposed skin of the elderly, and therefore, an association with UV has long been suspected. Eighteen fibrohistiocytic skin lesions comprising AFX $(n=7)$, storiform-pleomorphic type MFH centered in the subcutis (superficial MFH; S-MFH; $n=4$ ) and benign fibrous histiocytoma (BFH; $n=7$ ) were used for immunohistochemical and molecular analysis. Eight cases of deep MFH (D-MFH) were also analyzed for UV photoproduct expression for the purposes of comparison. Immunohistochemically, the CPD scores of AFX (3.6 \pm 0.4) were significantly higher than those of S-MFH $(1.3 \pm 0.8)$, D-MFH $(0.8 \pm 0.5)$, or BHF $(1.4 \pm 0.7)$; however, the 64PP scores were extremely low in all these tumors $(\mathrm{AFX}, 0.1 \pm 0.1$; S-MFH, $0.0 \pm 0.0$; D-MFH, $0.0 \pm 0.0$; and BHF, $0.0 \pm 0.0$ ). AFX, S-MFH, and BFH showed immunoexpression for p53 (2/7, $2 / 4$, and $0 / 7$ ), respectively. p53 mutations were detected in AFX $(4 / 6 ; 67 \%)$ and S-MFH $(1 / 4 ; 25 \%)$, but not in BFH $(0 / 5 ; 0 \%)$ using polymerase chain reaction-single-strand conformation polymor-

Copyright () 2001 by The United States and Canadian Academy of Pathology, Inc.

VOL. 14, NO. 6, P. 581, 2001 Printed in the U.S.A

Date of acceptance: February 14, 2001.

This word was supported by a Grant-in-Aid for Cancer Research from the Fukuoka Cancer Society, Fukuoka, Japan and by a Grant-in-Aid for General Scientific Research from the Ministry of Education, Science and Culture (Grants 09470052 and 12670167), Tokyo, Japan.

Address reprint requests to: Masazumi Tsuneyoshi, M.D., Department of Anatomic Pathology, Pathological Sciences, Graduate School of Medical Sciences, Kyushu University, 3-1-1 Maidashi, Higashi-ku, Fukuoka, 8128582, Japan; e-mail: masazumi@surgpath.med.kyushu-u.ac.jp; fax: $+81-92-642-5968$. phism, and all of the mutations in AFX were either C-T transitions or at dipyrimidine sites. In conclusion, AFX and S-MFH are both similar fibrohistocytic lesions; however, AFX has high immunoreactivity for CPDs compared with S-MFH, D-MFH, or BFH. These data suggest that CPDs may play an important role in the pathogenesis of AFX.

KEY WORDS: Atypical fibroxanthoma, Malignant fibrous histiocytoma, p53 Ultraviolet photoproducts. Mod Pathol 2001;14(6):581-588

Ultraviolet (UV) radiation is recognized as a major cause of human cancer (1). The mutation induced by UV radiation typically involves dipyrimidine sites with C-T or CC-TT double transitions $(2,3)$. UV photoproducts such as cyclobutane pyrimidine dimers (CPDs) and pyrimidine-pyrimidone (6-4) photoproducts (64PPs) have been identified as playing an important role in skin cancer development in sun-exposed skin $(4,5)$. It has been reported that CPDs can severely interfere with the binding of several important cell-cycle regulatory and DNA damage-responsive transcription factors (6).

Helwig (7) initially designated the term atypical fibroxanthoma (AFX) in 1961. AFX is typically a nodular ulcerative lesion arising from the sunexposed skin of the head and neck in the elderly. AFX demonstrates multidirectional differentiation and morphologically heterogeneous features with a bimodal pattern of fibrohistiocytic and myofibroblastic phenotypes. Therefore, AFX would appear to arise from a common mesenchymal progenitor cell with the capacity to differentiate along multiple pathways (8).

Histologically, AFX has features indistinguishable from those of malignant fibrous histiocytoma $(\mathrm{MFH})$, which is one of the most common high- 
grade sarcomas occurring deep within soft tissue. For this reason, AFX is widely recognized as being a variant of MFH, which arises in the dermis $(9,10)$. Superficial malignant fibrous histiocytoma (SMFH), a term for MFH centered in the subcutis (9-11), also has a better prognosis compared with MFH deep within soft tissue $(11,12)$. Accordingly, a superficial location is thought to contribute toward the favorable clinical behavior noted in AFX (13), as well as in S-MFH.

Some investigations have proposed to show a difference between AFX and MFH. LN-2, the name given to an MHC class II-associated invariant chain, is a $35-\mathrm{kDa}$ protein expressed by preB cells. Recently, it has been reported not only that reduced immunoexpression for LN-2 in AFX is a marker with which to distinguish it from MFH but also that an acquisition of LN-2 positivity is a marker of tumor progression in AFX (14). Another report demonstrated UV-induced p53 mutations occurring at dipyrimidine sites in AFX, suggesting the central role of UV radiation in the pathogenesis of AFX, unlike the case with MFH (15).

In the present study, we examined the immunohistochemical expressions of UV photoproducts (CPDs and 64PPs) and p53, as well as p53 mutations in AFX, in an attempt to clarify the association between AFX and UV radiation. Pleomorphic type superficial MFH, which is centered in the subcutis, and benign fibrous histiocytoma (BFH) were used for the purposes of comparison.

\section{MATERIALS AND METHODS}

\section{Specimens}

Eighteen fibrohistiocytic lesions comprising seven cases of atypical fibroxanthoma AFX, four cases of S-MFH, and seven cases of BFH were collected from the histopathological files at our institute. We used the term $S$-MFH for MFH centered in the subcutis, according to previous reports (9-11). Formalin-fixed paraffin-embedded tissue blocks of these cases were used for immunohistochemical and molecular analysis. Eight cases of D-MFH, which occurred in tissue deeper than the subcutis, were analyzed as a control immunohistochemical study of UV photoproducts. These D-MFH cases were from the thigh (three cases), the upper arm (two cases), the retroperitoneum (one case), the abdominal wall (one case) and the leg (one case), with ages ranging from 42 to 75 (mean: 63) years. In this study, we only used storiform-pleomorphictype MFH cases, and myxoid-type MFH cases were excluded. In addition, the cases of benign fibrous histiocytoma and D-MFH were selected at random.

\section{Immunohistochemical Staining}

Immunohistochemical analysis was performed using mouse IgG monoclonal antibodies against cyclobutane pyrimidine dimers (CPDs; TDM-2; 16), pyrimidine-pyrimidone (6-4) photoproducts (64PPs; 64M-2; 16), and p53 (PAb1801; Oncogene Research Products, Cambridge, MA).

Four-micrometer-thick histological sections of $10 \%$ formalin-fixed, paraffin-embedded materials were cut, mounted on glass slides coated by 3-aminopropyltriethoxysilane, and air-dried overnight at room temperature. The sections were deparaffinized in xylene and rehydrated in ethanol. After dehydration, endogenous peroxidase was blocked by methanol containing $0.3 \% \mathrm{H}_{2} \mathrm{O}_{2}$ for 30 minutes, in all of the above antibodies, with the exception of TDM-2 and 64M-2. The sections were incubated with the primary antibody at $4^{\circ} \mathrm{C}$ overnight, followed by reaction with the streptavidin-biotin complex method using an SAB-PO kit (Nichirei, Tokyo, Japan). The sections were then finally reacted in a 3,3' diaminobenzidine, peroxytrichloride substrate solution, counterstained with methyl green, or hematoxylin, and then mounted.

As for the antibodies for p53, specimens were pretreated by heating in a microwave oven. In the case of the antibody for CPDs, after dehydration, specimens were incubated in $3 \% \mathrm{H}_{2} \mathrm{O}_{2}$ for $10 \mathrm{~min}$ utes to inactivate endogenous peroxidase and in $0.1 \% \mathrm{CaCl}_{2}-0.1 \mathrm{~m}$ Tris-HCl buffer ( $\mathrm{pH} 7.5$ ) with $0.1 \%$ trypsin for 5 minutes at room temperature. Then, nuclear DNA was denatured using $70 \mathrm{~mm} \mathrm{NaOH}$ in $70 \%$ ethanol for 2 minutes at room temperature, followed by washing twice for 30 seconds each in $100 \mathrm{~mm}$ Tris- $\mathrm{HCl}$ (pH 7.5) in 70\% ethanol, twice for 10 minutes each in $70 \%$ ethanol and twice for 5 minutes each in phosphate buffered saline (PBS; 17). After these pretreatments, immunohistochemical staining was performed as for the other antibodies. The dilutions of primary antibodies were $1: 1,000$ for anti-CPDs and anti-64PPs and 1:100 for anti-p53.

\section{Assessment of Immunoreactivity}

Because the nuclear intensities of TDM-2 and $64 \mathrm{M}-2$ are dose dependently related to UV exposure (18), we evaluated the immunoreactivities of these antibodies in the nuclei of tumor cells semiquantitatively. The scoring system we used was as follows; 0 , absent immunoreactivity in cells; $1+$, a focal weak nuclear immunoreactivity in $<50 \%$ of cells; $2+$, a focal strong nuclear immunoreactivity in $<50 \%$ of cells; $3+$, a diffuse weak nuclear immunoreactivity in $>50 \%$ of cells; and $4+$, a diffuse strong nuclear immunoreactivity in $>50 \%$ of cells. All scores greater than 0 were interpreted as a positive 
result, whereas a score of 0 was interpreted as a negative result.

If $>5 \%$ of tumor cells showed apparent nuclear immunoreactivities for $\mathrm{p} 53$, then the case was classed as demonstrating a positive result.

\section{Polymerase Chain Reaction-Single-Strand Conformation Polymorphism}

We used the polymerase chain reaction-singlestrand conformation polymorphism (PCR-SSCP) procedure to detect p53 mutations at Exons 5 to 8 using the commercial primers (Clontech, Palo Alto, CA; Exons 5 and 6) and original primers (Exons 7 and 8). Table 1 summarizes the primers used in this study. DNA sequences for each exon were amplified for the first PCR using each primer for 40 cycles $\left(95^{\circ} \mathrm{C}\right.$ for 1 minute, $66^{\circ} \mathrm{C}$ for 1 minute and $72^{\circ} \mathrm{C}$ for 2 minutes). The PCR products were electrophoresed through $2 \%$ agarose gel with ethidium bromide, then digested from the agarose gels and reamplified by the same primers used for the first PCR for 15 cycles $\left(94^{\circ} \mathrm{C}\right.$ for 30 seconds and $60^{\circ} \mathrm{C}$ for 2 minutes). The reamplified products were diluted 1:1 in loading buffer ( $94 \%$ formamide, $10 \mathrm{mg}$ bromphenol blue, $0.05 \%$ xylene cyanol), denatured by heating at $96^{\circ} \mathrm{C}$ for 5 minutes, and snap-frozen on dry ice before being loaded onto $12.5 \%$ polyacrylamide gel. Electrophoresis was carried out at $5^{\circ} \mathrm{C}$ for 120 minutes at a constant power of $600 \mathrm{~V}$ using an electrophoretic apparatus (GenePhor System, Amersham Pharmacia Biotech, Tokyo, Japan). After electrophoresis, gels were stained using a DNA silver-staining kit (Hoefer Automated Gel Stainer, Amersham Pharmacia Biotech, Tokyo, Japan).

\section{Direct Sequencing}

After samples of the abnormally shifted p53 bands detected by PCR-SSCP were obtained from each gel and amplified, the amplified products were purified by centrifugal filter devices of Microcon (Millipore, Bedford, MA). After the purification, direct sequencing was carried out by the dideoxy chain termination method using a Perkin Elmer ABI

TABLE 1. PCR Primers Used to Amplify DNA for SSCP

\begin{tabular}{|c|c|c|}
\hline Gene & Strand & PCR Primers \\
\hline \multicolumn{3}{|l|}{ p53 } \\
\hline \multirow[t]{2}{*}{ Exon 5} & sense & 5'-СТСТTССТGCAGTACTCСССТGC-3' \\
\hline & antisense & 5'-GCCCCAGCTGCTCACCATCGCTA-3' \\
\hline \multirow{2}{*}{ Exon 6} & sense & 5'-GATTGCTCTTAGGTCTGGCCCCTC-3' \\
\hline & antisense & 5'-GGCCACTGACAACCACCCTTAACC-3' \\
\hline \multirow[t]{2}{*}{ Exon 7} & sense & 5'-GCTTGCCACAGGTCTCCCCAAG-3' \\
\hline & antisense & 5'-AGGGTGGCAAGTGGCTCCTGAC-3' \\
\hline \multirow[t]{2}{*}{ Exon 8} & sense & 5'-TGGTAATCTACTGGGACGGA-3' \\
\hline & antisense & 5'-GCTTAGTGCTCCCTGGGGGC-3' \\
\hline
\end{tabular}

PCR, polymerase chain reaction; SSCP, single-strand conformation polymorphism.
Prism 310 sequence analyzer (Applied Biosystems, Foster City, CA).

\section{Statistical Analysis}

Data are shown as the mean \pm SD and were analyzed by Mann-Whitney $U$ test. A calculated $P$ value of $<.05$ was considered to indicate significant difference.

\section{RESULTS}

\section{Clinical Features}

The clinical features are listed in Table 2. The ages of patients with AFX, S-MFH, and BFH ranged from 46 to 84 years, 48 to 71 years, and 18 to 38 years, respectively. The average ages of patients with these lesions were as follows: AFX cases (66.0 years), S-MFH cases (58.3 years), and BFH cases (29.6 years), in descending order. AFX showed a male predominance by six to one (M/F: 6/1), S-MFH was evenly distributed, with two males to two females (M/F: 1/1), whereas BFH showed a female predominance of two males to five females (M/F: 1/2.5). AFX occurred on the sun-exposed skin of the head, neck, and finger $(6 / 7 ; 86 \%)$, except for one case, which occurred in the leg $(1 / 7 ; 14 \%)$, whereas all cases of S-MFH occurred on the trunk and proximal extremities $(4 / 4 ; 100 \%)$, which were shielded from sun exposure. In contrast, BFH occurred at various sites without showing any special tendency. The average sizes of these lesions were as follows: S-MFH, $3.0 \mathrm{~cm}$; AFX, $1.6 \mathrm{~cm}$; and $\mathrm{BFH}, 0.9$ $\mathrm{cm}$, in descending order, with a significant difference between each of them $(P<.05)$. Furthermore, in our series, recurrence was recognized in two of the four S-MFH cases (Cases S4 and S5; 2/4; 50\%) but not in any of the AFX $(0 / 7 ; 0 \%)$ or BFH $(0 / 7 ; 0 \%)$ cases.

\section{Histological Features}

AFX was a nodular ulcerative lesion, composed of various proportions of smaller-sized spindled cells and pleomorphic epithelioid cells arranged in a haphazard or disorderly pattern (Figs. 1 and 2). S-MFH also consisted of fibrohistiocytic cells with pleomorphism arranged in short fascicles or a vague storiform pattern. Both AFX and S-MFH had mimicking histological features. BFH consisted of fibroblastic cells and occasionally rounded histiocytic cells arranged in short interlacing fascicles or a vague storiform pattern, with the overlying epidermis frequently showing some degree of hyperplasia. The tumor cells of $\mathrm{BFH}$ demonstrated no pleomorphism.

Solar elastosis was observed in three out of the four AFX cases. These three cases occurred on the 
TABLE 2. Molecular and Immunohistochemical Analysis of Cutaneous Fibrohistiocytic Lesions

\begin{tabular}{|c|c|c|c|c|c|c|c|c|c|c|c|}
\hline \multirow{2}{*}{ Case } & \multirow{2}{*}{ Lesion } & \multirow{2}{*}{ Age/Sex } & \multirow{2}{*}{ Location } & \multirow{2}{*}{ Size } & \multirow{2}{*}{$\begin{array}{c}\text { Solar } \\
\text { Elastosis }\end{array}$} & \multirow{2}{*}{ Recurrence } & \multicolumn{2}{|c|}{ p53 Mutation (Exons 5-8) } & \multirow{2}{*}{$\begin{array}{l}\text { p53 } \\
\text { IHC }\end{array}$} & \multirow{2}{*}{$\begin{array}{c}\text { CPDs } \\
\text { IHC Score }\end{array}$} & \multirow{2}{*}{$\begin{array}{c}\text { 64PPs } \\
\text { IHC Score }\end{array}$} \\
\hline & & & & & & & Mutation & Exon/codon & & & \\
\hline A3 & AFX & $82 / \mathrm{M}$ & Scalp & 1.0 & + & - & $\mathrm{ND}$ & $\mathrm{ND} / \mathrm{ND}$ & - & 4 & 1 \\
\hline A7 & AFX & $84 / \mathrm{M}$ & Face & 1.0 & + & - & TGCa-TGTa (silent) & $7 / 242$ & - & 1 & 0 \\
\hline A10 & AFX & $65 / \mathrm{M}$ & Auricle & 2.0 & NA & - & - & $-1-$ & + & 4 & 0 \\
\hline A14 & AFX & $71 / \mathrm{M}$ & Auricle & 1.0 & + & - & GTT-GGT (Val-Gly) & $5 / 172$ & + & 4 & 0 \\
\hline A16 & AFX & $50 / \mathrm{M}$ & Finger & 3.0 & NA & - & CACt-CATt (silent) & $7 / 233$ & - & 4 & 0 \\
\hline A17 & AFX & $46 / \mathrm{M}$ & Finger & 2.0 & NA & - & GGCt-GGTt (silent) & $7 / 226$ & - & 4 & 0 \\
\hline A19 & AFX & $64 / \mathrm{F}$ & Leg & 1.0 & - & - & - & $-1-$ & - & 4 & 0 \\
\hline S3 & S-MFH & $48 / \mathrm{F}$ & Thigh & 3.0 & - & - & - & $-1-$ & + & 0 & 0 \\
\hline $\mathrm{S} 4$ & S-MFH & $52 / \mathrm{F}$ & Chest wall & 2.5 & \pm & + & GGG-GGT (silent) & $8 / 279$ & + & 3 & 0 \\
\hline S5 & S-MFH & $62 / \mathrm{M}$ & Groin & 4.5 & - & + & - & $-1-$ & - & 2 & 0 \\
\hline $\mathrm{S} 6$ & S-MFH & $71 / \mathrm{M}$ & Knee & 2.0 & - & - & - & $-1-$ & - & 0 & 0 \\
\hline B8 & $\mathrm{BFH}$ & $18 / \mathrm{F}$ & Thigh & 0.8 & - & - & - & $-1-$ & - & 3 & 0 \\
\hline B9 & $\mathrm{BFH}$ & $38 / \mathrm{F}$ & Back & 1.0 & - & - & ND & $\mathrm{ND} / \mathrm{ND}$ & - & 3 & 0 \\
\hline B12 & $\mathrm{BFH}$ & $32 / \mathrm{M}$ & Thigh & 0.8 & - & - & - & $-1-$ & - & 4 & 0 \\
\hline B13 & $\mathrm{BFH}$ & $35 / F$ & Leg & 1.0 & - & - & $\mathrm{ND}$ & $\mathrm{ND} / \mathrm{ND}$ & - & 0 & 0 \\
\hline B16 & $\mathrm{BFH}$ & $30 / \mathrm{F}$ & Chest wall & 0.5 & - & - & - & $-1-$ & - & 0 & 0 \\
\hline B17 & $\mathrm{BFH}$ & $23 / \mathrm{M}$ & Forearm & 1.0 & - & - & - & $-1-$ & - & 0 & 0 \\
\hline B21 & BFH & $31 / \mathrm{F}$ & Leg & 1.3 & - & - & - & $-1-$ & - & 0 & 0 \\
\hline
\end{tabular}

AFX, atypical fibroxanthoma; S-MFH, superficial malignant fibrous histiocytoma; S-P type, storiform pleomorphic type; BFH, benign fibrous histiocytoma; IHC, immunohistochemistry; Val, valine; Gly, glycine; ND, not done; NA, not assessed; CPDs, cyclobutane pyrimidine dimers; 64PPs, pyrimidine-pyrimidone (6-4) photoproducts.

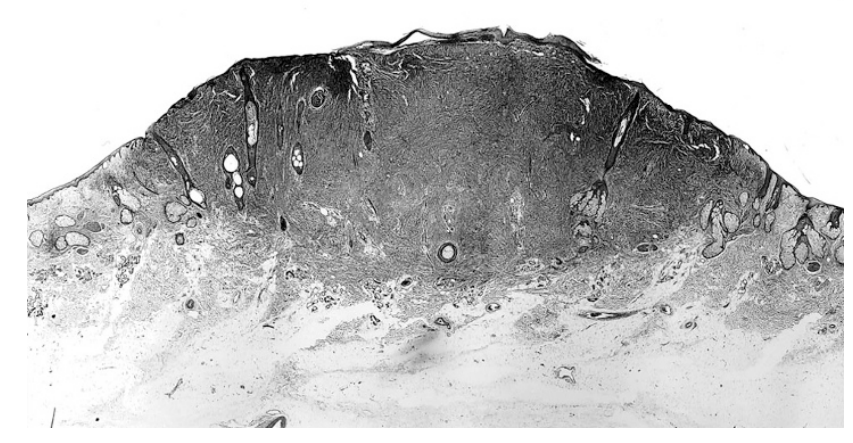

FIGURE 1. Atypical fibroxanthoma, showing an exophytic cellular nodule with ulceration of the overlying epidermis. The nodule is restricted to the reticular dermis. (Hematoxylin and eosin, original magnification, $8 \times$ ).

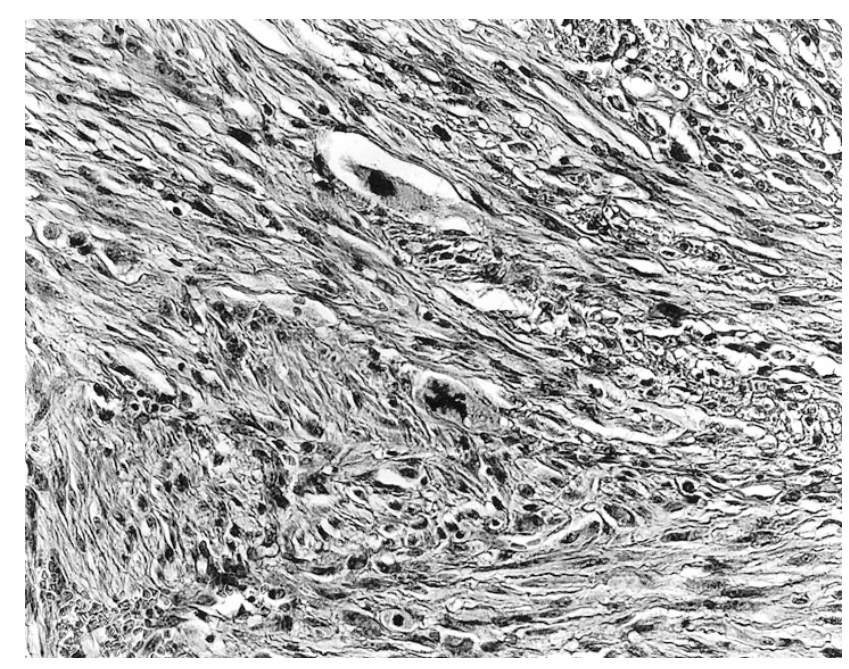

FIGURE 2. Atypical fibroxanthoma, demonstrating proliferation of atypical spindled cells in fascicles. Atypical mitosis can be observed. (Hematoxylin and eosin, original magnification, 200×). sun-exposed skin of the head and neck (scalp, face, and auricle, respectively), but solar elastosis was absent in the one case occurring on the leg. The other three cases (two on the finger and one on the auricle) could not be assessed because they were resected marginally and did not contain normal tissue within the specimen. With the exception of one case that occurred on the chest wall and had slight solar elastosis, none of the four S-MFH cases or seven BFH cases showed prominent solar elastosis (Table 2).

\section{Immunohistochemistry}

In normal resected skin tissue, CPD expressions were seen in the epidermis, but such expression was decreased in the hyperplastic epidermis in the BFH cases. The sweat gland, sweat gland duct, and hair bulb expressed CPDs partially, but these expressions were absent in the sebaceous gland, whereas the expression of 64PPs was virtually absent in the epidermis and other epidermal appendages. Immunohistochemical results of AFX, S-MFH, and BFH are summarized in Table 2. Immunohistochemical expression and CPDs scores were as follows: AFX (7/7; 100\%; mean; $3.6 \pm 0.4)$, S-MFH $(2 / 4 ; 50 \%$; mean, $1.3 \pm 0.8)$, and $\mathrm{BFH}(3 / 7 ; 43 \%$; mean, $1.4 \pm 0.7$; Fig. 3$)$, in contrast to $\mathrm{D}-\mathrm{MFH}(3 / 8$; $38 \%$; mean, $0.8 \pm 0.5)$. Those for $64 \mathrm{PPs}$ were AFX ( $1 / 7$; $14 \%$; mean, $0.1 \pm 0.1)$, S-MFH $(0 / 4 ; 0 \%$; mean, $0.0 \pm 0.0)$, and BFH (0/7; $0 \%$; mean, $0.0 \pm 0.0)$, in contrast to D-MFH (0/8; $0 \%$; mean, $0.0 \pm 0.0)$. AFX showed significantly higher scores for CPDs than did S-MFH, D-MFH, or BFH $(P<.05$; Table 3$)$. The normal epidermis and epidermal appendages seen 


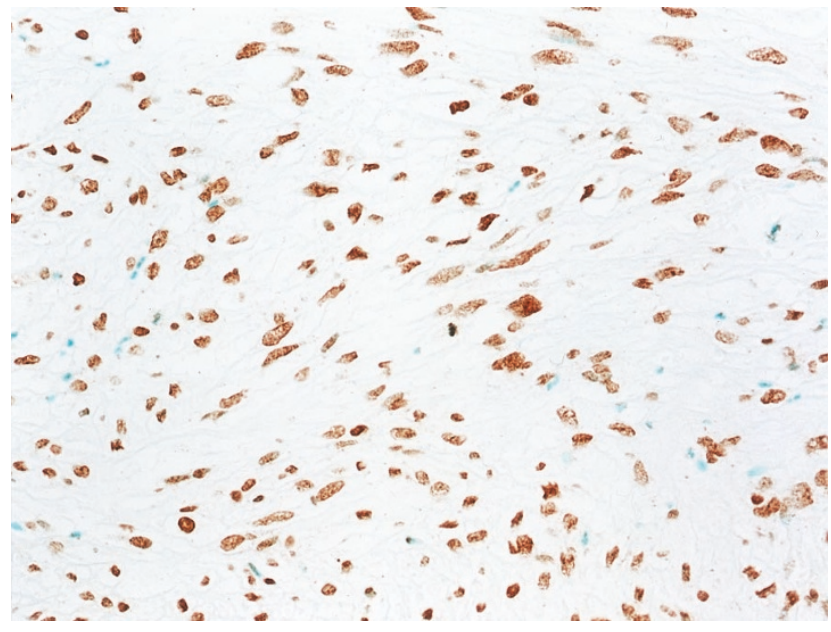

FIGURE 3. Atypical fibroxanthoma shows positive nuclear immunoreaction for cyclobutane pyrimidine dimers. (Immunohistochemistry, original magnification, 210×)

TABLE 3. Photoproducts in Fibrohistiocytic Lesions

\begin{tabular}{lcc}
\hline \multicolumn{1}{c}{ Group } & $\begin{array}{c}\text { CPDs } \\
\text { (Positive/Total) }\end{array}$ & $\begin{array}{c}\text { 64PPs } \\
\text { (Positive/Total) }\end{array}$ \\
\hline AFX $(n=7)$ & $3.6 \pm 0.4(7 / 7)^{\mathrm{b}}$ & $0.1 \pm 0.1(1 / 7)$ \\
S-MFH $(n=4)$ & $1.3 \pm 0.8(2 / 4)^{\mathrm{b}}$ & $0.0 \pm 0.0(0 / 4)$ \\
D-MFH $\left(n=8^{\mathrm{a}}\right)$ & $0.8 \pm 0.5(3 / 8)^{\mathrm{b}}$ & $0.0 \pm 0.0(0 / 8)$ \\
$\mathrm{BFH}\left(n=7^{\mathrm{a}}\right)$ & $1.4 \pm 0.7(3 / 7)$ & $0.0 \pm 0.0(0 / 7)$ \\
\hline
\end{tabular}

AFX, atypical fibroxanthoma; S-MFH, superficial malignant fibrous histiocytoma; D-MFH, deep malignant fibrous histiocytoma; BFH, benign fibrous histiocytoma; CPDs, cyclobutane pyrimidine dimers; 64PPs, pyrimidine-pyrimidone (6-4) photoproducts.

${ }^{\mathrm{a}} \mathrm{D}-\mathrm{MFHs}$ and BFHs were selected at random from our histological files.

${ }^{\mathrm{b}} P<.05$.

in AFX and BFH cases also expressed CPDs similar to normal tissue; however, the expression in the epidermis of AFX cases seemed to be stronger in intensity than that of BFH cases. Positive nuclear staining for p53 was found in two of the seven AFX cases $(2 / 7 ; 29 \%)$ and in two out of the four S-MFH cases $(2 / 4 ; 50 \%)$, but not in any of the BFH cases (0/7; 0\%; Fig. 4).

\section{p53 Mutation}

Table 2 also shows the molecular data for p53 mutation. AFX showed p53 mutations in four of the six cases of AFX (4/6; 67\%); Case A7 (Exon 7, Codon 242, TGCa-TGTa [silent]), Case A14 (Exon 5, Codon 172, GTT-GGT [Val-Gly]), Case A16 (Exon 7, Codon 233, CACt-CATt [silent]), and Case A17 [Exon 7, Codon 226, GGCt-GGTt [silent]). Among these four mutations, three were C-T transitions (A7, A16, and A17), and three occurred in the dipyrimidine sites (A14, A16, and A17). As for the type of base substitution, one case was missense mutation, and the other three were silent mutations (Figs. 5 and 6). S-MFH showed p53 mutations in one of the four cases (25\%) in S4 (Exon 8, Codon 279, GGG-GGT

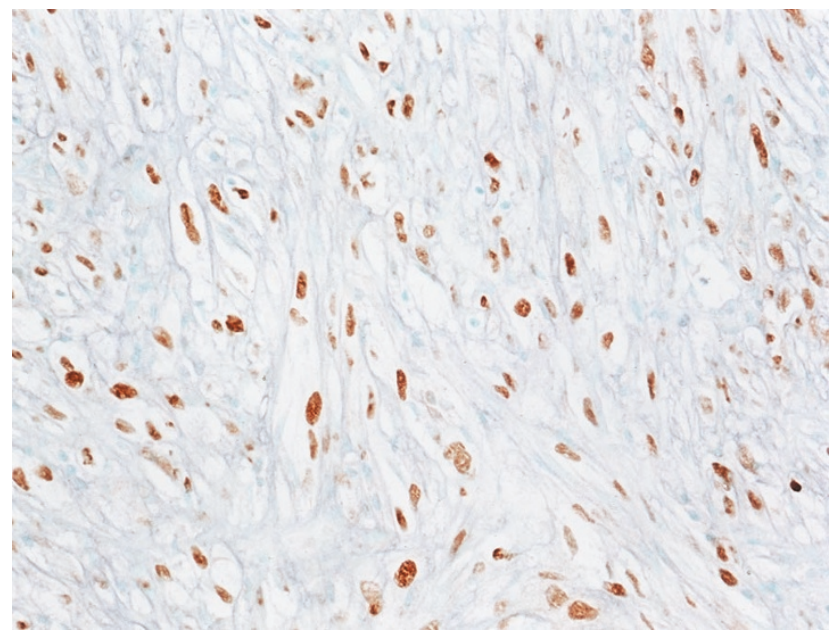

FIGURE 4. Atypical fibroxanthoma, showing positive nuclear immunoreaction for p53 (Case A14). (Immunohistochemistry, original magnification, $210 \times$ ).

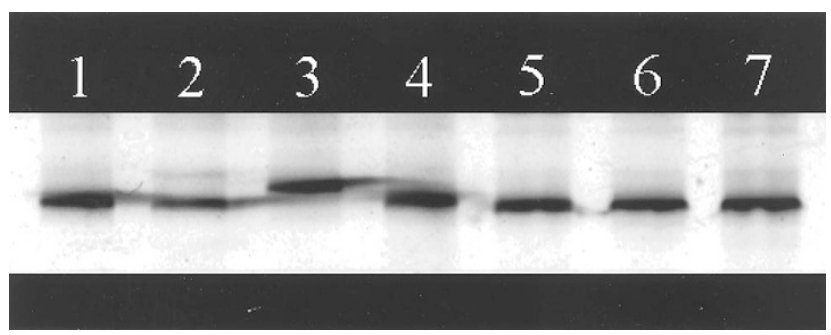

FIGURE 5. Polymerase chain reaction-single-strand conformation polymorphism analysis for p53 gene. Aberrant bands can be seen in Lane 3 .

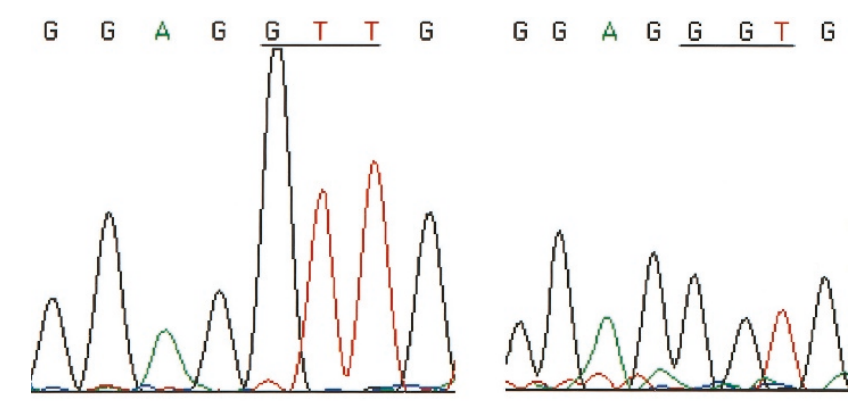

FIGURE 6. Atypical fibroxanthoma (Case A14). Direct sequencing was performed on the sample in Lane 3 of Fig. 5. The figure shows the p53 sense sequence and indicates that the second position of Codon 172 (Exon 5) of the sense strand was mutated from $T$ to $G$, this change being the code for glycine instead of valine (right). The control shows no mutation and encodes valine (left).

[silent]). The mutation case among the S-MFH cases was a silent mutation, which was not located in a dipyrimidine site. BHF showed no p53 mutation in Exons 5 to 8 in this study $(0 / 5 ; 0 \%)$.

\section{DISCUSSION}

The UV spectrum is divided into UVC (200-280 nm), UVB (280-320 nm), and UVA (320-400 nm). UVA is less likely to cause DNA damage, and UVC is 
effectively absorbed by the ozone layer. On the other hand, UVB plays a significant role in UVinduced DNA-damage, and its wavelengths penetrate the epidermis, being almost completely absorbed in the upper dermis (19).

The wild-type p53 gene plays an essential part in the maintenance of cellular genetic stability after a DNA-damaging event such as exposure to UV radiation (20). A cellular stress response to UV radiation depends upon the UV dose. DNA repair occurs after low doses and apoptosis after high doses, although both mechanisms depend upon wild-type p53 function (21). Mutations of p53 are found in various malignant tumors. UV radiation is thought to be a major cause of human skin cancer (1). The predominant mutation patterns of $\mathrm{C}-\mathrm{T}$ transitions and CC-TT double transitions at dipyrimidine sites in the p53 gene are considered to be specifically induced by UV radiation $(2,3)$. These UV-induced p53 mutations occurring at dipyrimidine sites have been demonstrated in AFX, suggesting a central role of UV radiation in the development of AFX (15). In the current study, p53 immunoexpression was seen in the AFX $(2 / 7 ; 29 \%)$ and S-MFH $(2 / 4 ; 50 \%)$ cases, but not in any of the BHF cases $(0 / 7 ; 0 \%)$, and we detected p53 mutations in four of six AFX cases $(4 / 6 ; 67 \%)$ and in one of four S-MFH cases $(1 / 4$; $25 \%)$, but not in any of the BFH cases $(0 / 5 ; 0 \%)$. There was no exact correlation between the cases with p53 mutation and p53 immunoexpression in AFX. Three of the four mutations occurring in the AFX cases were $\mathrm{C}-\mathrm{T}$ transitions, and three were at dipyrimidine sites; however, these kinds of mutation were not seen in the S-MFH cases with p53 mutation. Therefore, UV radiation seemed to be more closely involved in the pathogenesis of AFX than in that of S-MFH or BFH. AFX is known to occur in two clinical settings, on the head and neck of older people and on the extremities of younger people (22). In a previous report, some of the later cases were assumed to be examples of atypical benign fibrous histiocytoma (23). In this study, there were two AFX cases on the finger, and these were the two youngest patients in our series of AFX. It should be noted that these cases were classed as AFX cases, on the basis that they both had p53 mutations associated with UV radiation.

The formation of DNA photoproducts by UV radiation is responsible for the induction of mutations and the development of skin cancer (24). Among these photoproducts, CPDs and 64PPs are the most prominent, appearing to be involved in mutagenesis and carcinogenesis $(4,5)$. The photoproducts are removed in normal cells by DNA excision repair. Unrepaired photoproducts are also thought to block replication, resulting in cell death. Alternatively, bypassing the unrepaired lesions during replication is considered to cause the incorpo- ration of an incorrect base opposite the photoproduct, consequently leading to a mutation (25).

The presence of CPDs strongly inhibits binding of the respective transcription factor complexes. UVinduced DNA photoproducts can severely interfere with the binding of several important cell-cycle regulatory and DNA damage-responsive transcription factors, including E2F, NF-Y, AP-1, NF $\kappa$ B, and p53 (6). 64PPs are generally repaired faster than CPDs (26), and therefore 64PPs appear less likely to become principal mutagenic lesions after UV radiation (27).

Unrepaired CPDs have been detected in actinic keratosis cells by an immunoblotting method and could be thought to reflect the genetic process in multistage carcinogenesis (28). In addition, a decreased ability to repair CPDs has been seen in patients who develop basal cell carcinoma on sunexposed skin (29). The immunohistochemical method in this study using specific antibodies against the photoproducts (CPDs and 64PPs) has been reported to be highly sensitive for detecting photoproducts in formalin-fixed and paraffinembedded sections (17). Because the nuclear staining intensities of TDM-2 and 64M-2, which are the antibodies for CPDs and 64PPs respectively, are dose dependently related to UV exposure, the photoproducts could be detected semiquantitatively $(16,17)$.

In the current study, accumulation of CPDs was highly visible in the AFX cases compared with S-MFH, D-MFH, or BFH cases; however, the accumulation of 64PPs was either weak or else not detectable immunohistochemically in the AFX, $\mathrm{S}-\mathrm{MFH}, \mathrm{D}-\mathrm{MFH}$, and BHF cases. Therefore CPDs seem to be more important photoproducts than 64PPs in the development of AFX, as well as carcinomas in sun-exposed areas (30). However, because the number of cases used in this study was small, study of a large series would be appreciated.

The eight hotspots of codons 151, 177, 196, 245, 248, 278, 286, and 294 in Exons 5-8 of the p53 gene are frequently mutated in human nonmelanoma skin cancers $(3,18,31)$. The p53 mutations in Codons 151/152, 278, and 286 show a marked tendency to give rise to UV photoproducts (CPDs and 64PPs) after UV radiation. However, both types of photoproducts rarely form at sequences near Codons 245 and 248 (32). Moreover, slow repair of CPDs was seen at seven of those eight mutation hot spots in p53 in skin cancer, suggesting that repair efficiency may strongly contribute to the mutation spectrum in a cancer-associated gene (33). As for contribution to carcinogenesis, this would depend on whether the site is a "slow spot" for DNA repair, as well as on whether a mutation inhibits the function of p53 (18). The AFX cases used in the current study did not contain these hotspots of p53 muta- 
tion, and therefore we were not able to detect any unequivocal evidence that the same mechanism is involved in the development of AFX and skin cancer.

An association with UV radiation in the pathogenesis of AFX has already been postulated (15); nevertheless, it remains difficult to distinguish it from MFH because of the close resemblance microscopically between the two lesions. In the current study, most AFX cases occurred in sun-exposed skin $(6 / 7 ; 86 \%)$, whereas all the S-MFH cases occurred on the trunk and proximal extremities (4/4; $100 \%)$. In addition to the location, AFX and S-MFH differed in size (average size: AFX, $1.6 \mathrm{~cm}$; S-MFH, $3.0 \mathrm{~cm}$ ). Recurrence was recognized only in S-MFH cases (Cases S4 and S5, 2/4;50\%), but not in AFX cases $(0 / 7 ; 0 \%)$. The superficial location of AFX may contribute towards these differences between AFX and S-MFH; however, these differences could be associated with the peculiar pathogenesis of AFX regarding the relationship with UV radiation, which has also been documented by Dei Tos et al. (15).

In conclusion, despite the shared morphological features between AFX and S-MFH, AFX showed peculiar aspects with regard to its immunohistochemical expression for UV-induced photoproducts, as well as with regard to clinical findings such as site, size, and the rate of recurrence. The results show some relationship between UV radiation and AFX and imply that AFX has a different molecular pathogenesis from that of MFH.

Acknowledgments: The English used in this manuscript was revised by Miss K. Miller (Royal English Language Center, Fukuoka, Japan).

\section{REFERENCES}

1. Vitasa BC, Taylor HR, Strickland PT, Rosenthal FS, West S, Abbey $\mathrm{H}$, et al. Association of nonmelanoma skin cancer and actinic keratosis with cumulative solar ultraviolet exposure in Maryland watermen. Cancer 1990;65:2811-7.

2. Miller JH. Mutagenic specificity of ultraviolet light. J Mol Biol 1985;182:45-65.

3. Brash DE, Rudolph JA, Simon JA, Lin A, McKenna GJ, Baden HP, et al. A role for sunlight in skin cancer: UV-induced p53 mutations in squamous cell carcinoma. Proc Natl Acad Sci U S A 1991;88:10124-8.

4. Hart RW, Setlow RB, Woodhead AD. Evidence that pyrimidine dimers in DNA can give rise to tumors. Proc Natl Acad Sci U S A 1977;74:5574-8.

5. Moan J, Peak MJ. Effects of UV radiation of cells. J Photochem Photobiol B 1989;4:21-34.

6. Tommasi S, Swiderski PM, Tu Y, Kaplan BE, Pfeifer GP. Inhibition of transcription factor binding by ultraviolet-induced pyrimidine dimers. Biochemistry 1996;35:15693-703.

7. Helwig EB. Atypical fibroxanthoma. Proceedings of 18th Annual Tumor Seminar of San Antonio Society of Pathologists. Tex State J Med 1963;59:664-7.

8. Longacre TA, Smoller BR, Rouse RV. Atypical fibroxanthoma. Multiple immunohistologic profiles. Am J Surg Pathol 1993; 17:1199-209.
9. Enzinger FM, Weiss SW. Soft tissue tumors. 3rd ed. St. Louis: CV Mosby; 1995.

10. Wick MR, Fitzgibbon J, Swanson PE. Cutaneous sarcomas and sarcomatoid neoplasms of the skin. Semin Diagn Pathol 1993;10:148-58.

11. Shinjo K. Analysis of prognostic factors and chemotherapy of malignant fibrous histiocytoma of soft tissue: a preliminary report. Jpn J Clin Oncol 1994;24:154-9.

12. Rooser B, Willen H, Gustafson P, Alvegard TA, Rydholm A. Malignant fibrous histiocytoma of soft tissue. A populationbased epidemiologic and prognostic study of 137 patients. Cancer 1991;67:499-505.

13. Helwig EB, May D. Atypical fibroxanthoma of the skin with metastasis. Cancer 1986;57:368-76.

14. Lazova R, Moynes R, May D, Scott G. LN-2 (CD74). A marker to distinguish atypical fibroxanthoma from malignant fibrous histiocytoma. Cancer 1997;79:2115-24.

15. Dei Tos AP, Maestro R, Doglioni C, Gasparotto D, Boiocchi $\mathrm{M}$, Laurino L, et al. Ultraviolet-induced p53 mutations in atypical fibroxanthoma. Am J Pathol 1994;145:11-7.

16. Mori T, Nakane M, Hattori T, Matsunaga T, Ihara M, Nikaido O. Simultaneous establishment of monoclonal antibodies specific for either cyclobutane pyrimidine dimer or (6-4) photoproduct from the same mouse immunized with ultraviolet-irradiated DNA. Photochem Photobiol 1991;54: 225-32.

17. Qin X, Zhang S, Nakatsuru Y, Oda H, Yamazaki Y, Suzuki T, et al. Detection of active UV-photoproduct repair in monkey skin in vivo by quantitative immunohistochemistry. Cancer Lett 1994;83:291-8.

18. Nataraj AJ, Trent JC 2nd, Ananthaswamy HN. p53 gene mutations and photocarcinogenesis. Photochem Photobiol 1995;62:218-30.

19. Meunier L. Ultraviolet light and dendritic cells. Eur J Dermatol 1999;9:269-75.

20. Kastan MB, Onyekwere O, Sidransky D, Vogelstein B, Craig RW. Participation of p53 protein in the cellular response to DNA damage. Cancer Res 1991;51:6304-11.

21. Li G, Ho VC. p53-dependent DNA repair and apoptosis respond differently to high- and low-dose ultraviolet radiation. Br J Dermatol 1998;139:3-10.

22. Dahl I. Atypical fibroxanthoma of the skin. A clinicopathological study of 57 cases. Acta Pathol Microbiol Immunol Scand 1976;84:183-97.

23. Beham A, Fletcher CD. Atypical 'pseudosarcomatous' variant of cutaneous benign fibrous histiocytoma: report of eight cases. Histopathology 1990;17:167-9.

24. Pfeifer GP. Formation and processing of UV photoproducts: effects of DNA sequence and chromatin environment. Photochem Photobiol 1997;65:270-83.

25. Kraemer KH. Sunlight and skin cancer: another link revealed. Proc Natl Acad Sci U S A 1997;94:11-4.

26. Mitchell DL. The relative cytotoxicity of (6-4) photoproducts and cyclobutane dimers in mammalian cells. Photochem Photobiol 1988;48:51-7.

27. Brash DE. UV mutagenic photoproducts in Escherichia coli and human cells: a molecular genetics perspective on human skin cancer. Photochem Photobiol 1988;48:59-66.

28. Hori M, Udono MU, Yoshida H, Urata Y, Koike K, Ihara M. Immunochemical detection of unrepaired cyclobutane-type pyrimidine dimers of DNAs extracted from human skin tumours. Arch Dermatol Res 1992;284:283-9.

29. Alcalay J, Freeman SE, Goldberg LH, Wolf JE. Excision repair of pyrimidine dimers induced by simulated solar radiation in the skin of patients with basal cell carcinoma. J Invest Dermatol 1990;95:506-9.

30. Qin X, Zhang S, Zarkovic M, Nakatsuru Y, Shimizu S, Yamazaki Y, et al. Detection of ultraviolet photoproducts in 
mouse skin exposed to natural sunlight. Jpn J Cancer Res 1996;87:685-90.

31. Ziegler A, Leffell DJ, Kunala S, Sharma HW, Gailani M, Simon JA, et al. Mutation hotspots due to sunlight in the p53 gene of nonmelanoma skin cancers. Proc Natl Acad Sci U S A 1993;90:4216-20.
32. Tornaletti S, Rozek D, Pfeifer GP. The distribution of UV photoproducts along the human p53 gene and its relation to mutations in skin cancer. Oncogene 1993;8:2051-7.

33. Tornaletti S, Pfeifer GP. Slow repair of pyrimidine dimers at p53 mutation hotspots in skin cancer. Science 1994;263: $1436-8$.

\section{Book Review}

\section{Schaeff MT, Hopster DJ: Post Mortem Tech- nique Handbook, 312 pp, London, Springer-Verlag, 2001 (\$89.00).}

The decline of utilization of the autopsy in American medicine is mirrored by the lack of an upto-date, authoritative text on autopsy pathology and technique. The tradition of books about autopsy technic is rich, beginning with Post Mortem Examinations by Virchow, a slender volume on autopsy methods, translated into English in 1891. In the 20th century a number of books gained wide acceptance and provided considerable information on technique, as well as macroscopic features. Many long-ago out of print books, such as Saphir's Autopsy Diagnosis and Technic, Mallory's Pathological Technique, and Rezek and Millard's Autopsy Pathology, remain valuable resources. For this reason, Post Mortem Technique Handbook, by Michael T. Scheaff and Deborah J. Hopster, was eagerly anticipated.

The authors intended to provide a "thorough and repeatable technique for a novice to follow." To a considerable degree, they have not accomplished this. Regrettably, the book is hampered by a style of writing that leaves something to be desired. In addition, there are errors as evidence that the authors/editors did not proofread the book very carefully. As one example, Figures 4.1 and 4.4 are exactly the same, although the legends differ. In general, the black-and-white illustrations are not excellent quality and certainly will not help the student learn how to perform an autopsy. For example, an inexperienced pathologist will have great difficulty understanding Figure 2.3. As a matter of fact, an experienced pathologist also will have some problems with this, and other, illustrations. Baker's Postmortem Examination, also long out of print, relied only on line drawings to effectively teach a novice how to perform a complete autopsy. Figure 5.3 does employ the device of indicating lines of sectioning on the gross picture. Does one use a scissor or a scalpel or a long knife? The beginner will not have an easy time. Figure 10.2 seems to be an example of what we have referred to as the "pep- peroni" dissection method. Here a spleen is sliced perpendicular to the long axis of the organ. Further, there is no ruler, precluding a reasonable estimation of the spleen size and weight. This is a poor lesson for the new pathologist who should be taught how to maximize the educational value of photographs.

There are a number of unnecessary repetitions. On page 1 we learn that, in the United Kingdom, only $10 \%$ of autopsies are performed outside the coroner's system. This is soon followed, on page 2 , by the information that $90 \%$ of autopsies are performed by coroners. Another example of lack of care in preparing this book can be found in the discussions of the method for identifying the thoracic duct, with one description on page 55 telling us to find the thoracic duct by moving the right lung forward and to the left and another on page 176 advising us to lift the left lung forward. Macroscopic dye techniques for recognizing early myocardial infarction appear on pages 104 and 229. The two sections are consistent, although slightly different, but it is not clear why this repetition, and others, are necessary.

The book provides information about both hospital-based autopsies and medical examiner's autopsies. This is also confusing for the learner, and much of the detail is not relevant for most pathologists in the United States. Much of the book is based on the methods used in daily practice that may not be familiar to American readers. For example, the authors regularly refer to a "PM40." With a little searching, one finds out that this is the name for a scalpel that is apparently commonly used in Great Britain.

For the new student of pathology, this book will not be particularly helpful. The more experienced practitioner, continuing to learn, may well find information to improve the approach to the autopsy.

\section{Stephen A. Geller \\ Cedars-Sinai Medical Center \\ Los Angeles, California}

